\title{
PELARANGAN IMPORT DRAMA REPUBLIK KOREA OLEH REPUBLIK RAKYAT TIONGKOK DALAM PERSPEKTIF NATIONAL INTERREST DAN HUBUNGAN INTERNASIONAL
}

\author{
I.Gst. Ngr. Hady Purnama Putera \\ Mahasiswa Program Pascasarjana Universitas Gadjah Mada Yogyakarta \\ Email : purnama623@gmail.com
}

\begin{abstract}
ABSTRAK
Kementerian Keamanan Publik Tiongkok memberi himbauan publik yang menyatakan bahwa, "Menonton drama Korea berbahaya dan bisa menyebabkan masalah hukum." Sepenggal berita yang dilansir beberapa media tersebut menjadi sebuah tanda tanya. Apakah secara ekonomi kuatnya gelombag "K-Wave" yang bermula beberapa tahun lalu sedemikian mengganggu perekonomian Tiongkok, ataukah ada hal yang bisa dipandang secara diplomatis mengapa Tiongkok melakukan aksi Boikot atas produk drama televisi asal Republik Korea atau K-drama ?. penelitian ini akan mencoba mencari sudut pandang lain tentang alasan Tiongkok melakukan boikot atas produk K-drama.
\end{abstract}

Kata Kunci : K-drama, Kepentingan Nasional, Propaganda, Boikot.

\section{ABSTRACT}

The Ministry of Public Security of China gave an appeal publicly stating that, "Watching Korean dramas dangerous and could cause legal problems." A piece of news reported by some media becomes a question mark. Are the boom of "K-Wave" Phenomenon that began a few years ago have such enormous economic power to disturbing China's economy, or there are things that can be viewed in diplomatic why China did boycott on television dramas product origin Republic of Korea or K-drama?. This research will try to find another point of view about the reasons for the Chinese to boycott the K-dramas as a export commodity.

Key Word: K-Drama, National Interest, Propaganda, Boycott.

\section{Pendahuluan}

Episode ke-10 drama yang dibintangi aktor Song Joong Ki tersebut, sukses menembus rating 39 persen. Kesuksesan tersebut berbanding lurus dengan penjualan hak cipta di televisi negara asing. Setelah stasiun televisi Jepang membelinya 100 juta won atau setara 1 milyar rupiah, kini stasiun televisi
Tiongkok kabarnya juga tertarik dengan Descendants of the Sun dan membelinya sebesar 260 juta won atau setara 2,6 milyar rupiah. Decendants of the Sun yang disiarkan di Platform video Tiongkok, barubaru ini juga menembus rekor. Episode ke-8 drama tersebut ditonton hingga 1,1 juta kali (www.tabloidbintang.com). kabar 
pencapaian besar produk export budaya populer asal Republik Korea (selanjutnya disebut Korea Selatan) ini diikuti kabar tidak menyenangkan dari tetangganya yakni Republik Rakyat Tiongkok (selanjutnya disebut Tiongkok.

Dilansir CNNIndonesia.com, Kementerian Keamanan Publik Tiongkok memberi himbauan publik yang menyatakan bahwa, "Menonton drama Korea berbahaya dan bisa menyebabkan masalah hukum. Masalah sosial menjadi alasan utama pelarangan produk budaya populer asal korea selatan ini di larang untuk beredar di Tiongkok, namun mengutip dari IBTimes, dampak buruk bukan satusatunya alasan pemerintah melarang drama Korea. Diduga, pelarangan itu juga diakibatkan hubugan tegang antara Korea dan Tiongkok. Kemungkinan besar itu karena keputusan Korea mendukung kebijakan misil Amerika Serikat. Di sisi lain, Tiongkok bersikap oposisi terhadap kebijakan itu (www.cnnindonesia.com).

Di sisi lain fakta bahwa drama korea bukan lagi sekedar bisnis hiburan yang menghasilkan pendapatan bagi selebriti dan sineas dalam negeri korea, namun sudah berkembang menjadi sebuah produk global yang adalah bentuk nantional branding dari republik korea itu sendiri. Menurut statistik Bank of Korea dari bidang ekspor budaya dan jasa hiburan, industri musik K-pop telah menghasilkan US\$794 juta tahun 2011 dan mengalami peningkatan $25 \%$ dari US\$637 juta di tahun 2010 seiring K-pop semakin diminati oleh masyarakat internasional (http://english.chosun.com).
Pendapatan yang sangat besar dari export produk industri hiburan korea memang memberi sumbangan yang besar kepada GDP (gross domestic product) korea, namun penting kiranya bagi penulis mengkaji lebih tentang sejauh apa, kepentingan nasional Tiongkok terganggu akibat begitu larisnya produk-produk drama televisi asal korea selatan sehingga harus menggambil kebijakan yang demikian keras hingga mengeluarkan peraturan boikot atas produk industri hiburan korea selatan tersebut. Apakah produk budaya populer asal korea selatan ini memang pada kenyataannya lebih dari sekedar bisnis hiburan yang menjadi komoditas export sehingga di satu sisi dipandang dapat mengganggu kepentingan nasional tiongkok?.

\section{Metode Penelitian}

Jenis penelitian yang digunakan dalam penulisan ini adalah jenis penelitian hukum normatif, karena meneliti sejarah hukum serta asasasas hukum, selain itu penelitian ini juga meneliti dan mengkaji peraturan-peraturan tertulis (Soerjono Soekanto;15). Karena penelitian ini adalah penelitian hukum normatif maka sumber datanya adalah berupa data sekunder yang berupa bahan hukum, baik bahan hukum primer maupun bahan hukum sekunder (Amiruddin, dan H.Zainal Asikin, 2003;118). Jenis pendekatan yang digunakan yang digunakan dalam penelitian ini adalah pendekatan sejarah, dan pendekatan konsep. Analissis terhadap bahan-bahan hukum yang telah diperoleh dilakukan dengan cara deskriptif, analisis, dan 
argumentatif ((Amiruddin, dan H.Zainal Asikin, 2003).

\section{Teori Kepentingan Nasional}

Kepentingan

nasional

merupakan konsepsi yang sangat umum tetapi merupakan unsur yang menjadi kebutuhan sangat vital bagi negara. Tujuan mendasar serta faktor paling menentukan yang memandu para pembuat keputusan dalam merumuskan politik luar negeri adalah kepentingan nasional. Kepentingan nasional adalah tujuantujuan yang ingin dicapai sehubungan dengan kebutuhan bangsa/negara atau sehubungan dengan hal yang dicita-citakan. "Kepentingan nasional sebagai kebutuhan dan keinginankeinginan oleh suatu negara yang berdaulat dalam berhubungan dalam negara berdaulat lainnya yang merupakan lingkungan eksternalnya." (Jack C Plano, and Roy Olton, 1999).

Dalam konsep kepentingan nasional, dikenal sebuah perspektif yang disebut perspektif realis (realist perspective). Perspektif realis berasumsi bahwa negara merupakan aktor utama dalam politik internasional (main unit of analysis). Negara adalah aktor rasional dimana kebijakan luar negeri diambil berdasarkan kepentingan dan tujuan nasional (Viotti, Paul. R. dan Mark V. Kauppi, 1999;55). Kesimpulannya adalah perspektif realis melihat kebijakan luar negeri sebagai refleksi kepentingan dan tujuan nasional. Keamanan negara dan kedaulatan wilayah adalah fokus analisisnya. Menurut Wight 1991 dalam Robert Jackson dan Georg Sorensen 2005, kaum realis menekankan "elemen anarki, politik kekuasaan, dan peperangan." (Jackson, Robert dan Georg Sorensen;2005) Artinya adalah bahwa dalam memahami atau menganalisa permasalahan yang menggunakan perspektif realis ini, penekanan masalahnya adalah pada ketiga elemen di atas sehingga ada penekanan pada kekuatan di bidang militer (military force).

Asumsi pendekatan ini adalah keyakinan bahwa isu-isu internasional mempunyai prioritas atau hierarki dimana keamanan nasional menempati urutan teratas. Keamanan nasional menempati prioritas teratas (top priority) karena berkaitan langsung dengan eksistensi sebagai negara yang berdaulat. Negara sebagai aktor utama berperan dalam mengamati kebijakan yang diarahkan kepada isu keamanan nasional. Asumsi tersebut diperkuat oleh Kenneth Walt yang mengatakan bahwa negara adalah aktor terpenting dalam interaksi hubungan internasional dimana proposisi teoritis utama mengarah kepada kompetisi kepentingan negara-negara untuk mendapatkan power atau keamanan (self interest states compete constantly for power or security) (Walts, Stephen. M, 1998;110). Negara-negara akan berlombalomba memperjuangkan kepentingan nasional masing-masing untuk mencapai suatu tujuan tertentu yaitu mendapatkan power (kekuasaan) atau keamanan.

\section{Drama Korea Sebagai Bentuk Soft Diplomacy}

Awalnya, SHI (study of international relations) didefinisikan sebagai studi tentang hubunganhubungan atar negara (Chris Brown;2001). Hubungan-hubungan tersebut hanya terbatas pada 
keamanan dan perang saja. Definisi tersebut berubah ketika aktor-aktor di dalam politik dunia bertambah dan bentuk hubungan menjadi lebih kompleks. Kini bisa dikatakan bahwa SHI adalah ilmu yang membahas tentang hubunganhubungan antar aktor, baik itu negara, non negara (seperti organisasi internasional dan perusahaan multinasional) bahkan individu di dalam sistem internasional. SHI dalam hal ini, melihat pada segala jenis hubungan "harmoni ataupun konflik, damai ataupun perang, sipil ataupun militer, politis maupun ekonomis" (J.C. Johari, 1985).

Perkembanagan panjang kajian Studi Hubungan Internasional mempengaruhi perkembangan kajian di bidang Hukum Diplomatik yang adalah salah satu penyusun dari studi hubungan internasional itu sendiri secara bertimbal balik. Dijelaskan oleh sir victor wellessley, diplomasi bukanlah merupakan kebijakan, tetapi lembaga untuk memberikan pengaruh terhadap kebijakan tersebut. Namun demikian, diplomasi dan kebijakan keduanya saling melengkapi karena seseorang tidak akan dapat bertindak tanpa kerja sama satu sama lain. Diplomasi tidak dapat dipisahkan dari politk luar negeri, tetapi keduanya bersamasama merupakan kebijakan eksekutif, seperti kebijakan untuk menetapkan strategi, diplomasi dan taktik (Sumaryo Suryokusumo, 2000;7). Diplomasi mengalami perkembangan dimana tidak lagi hanya didominasi oleh aktor-aktor negara. Penyerangan terhadap Amerika tanggal 11 september 2001 menjadi sebuah titik balik diplomasi yang disebut sebagai diplomasi publik. Istilah ini pertama kali dicetuskan oleh Edmund Gullion tahun 1965. Dalam pendapatnya disebutkan, melalui diplomasi publik ini, opini publik dapat berperan dalam rangka mendukung kebijakan negara. Lebih dari itu, publik juga dapat membantu mempengaruhi opini masyarakat negara lain tentang negaranya (Daniell S Papp, 1997;442). Dalam pelaksanaannya soft power menjadi sebuah instrument penting pendukung diplomasi publik ini. Negara melalui beberapa aktivitas melibatkan berbagai aktor dan organisasorganisasi yang memiliki akibat terhadap publik secara internasional, seperti melalui aktor-altor, galeri seni dan musik, kelompok media dan wartawan, masyarakat dan lembaga swadaya masyarakat, pengusaha dan produksinya, politisi, partai dan pakar politik, akademisi, universitas, pemimpin agama, kelompok agama, dan sebagainya (Josef Batora, 2005).

Bentuk paling nyata yang dapat dilihat dari penggunaan soft power dalam diplomasi publik ini dapat dilihat pada diplomasi budaya sebagai bagian tak terpisahkan dari diplomasi publik itu sendiri. Budaya sebagai alat diplomasi dijelaskan oleh Joseph Nye merupakan seperangkat kegiatan yang menciptakan makna bagi masyakrakat, dan memiliki banyak manifestasi. Biasanya hal ini akan dibedakan antara budaya tinggu seperti sastra, seni dan pendidikan yang melayani masyarakat elit, dan budaya populer yang berfokus pada hiburan masa (Joseph S. Nye, Jr., 2011). Pendapat lain tentang diplomasi budaya adalah bahwa diplomasi kebudayaan adalah strategi negara-negara berkembang, hal ini didasari bahwa diplomasi publik merupakan sebuah substansi politik 
luar negeri dalam pemanfaatannya bagi negara-negara yang sedang berkembang. Diplomasi kebudayaan merupakan bagian atau salah satu jenis dari begitu banyak diplomasi lain, artinya usaha suatu negara untuk memperjuangkan kepentingan nasionalnya dijalankan melalui dimensi kebudayaan, baik secara mikro melalui pendidikan, ilmu khas yang utama, misalnya propaganda dan lain-lain (Tulus Warsito \& Wahyuni Kartikasari, 2007; 2).

\section{Drama Korea dan Propaganda}

Menurut Grath S. Jowett dan Victoria O'Donnell (2010;1), propaganda adalah usaha dengan sengaja dan sistematis untuk membentuk persepsi,manipulasi pikiran, dan mengarahkan kelakuan untuk mendapatkan reaksi yang diinginkan penyebar propaganda. Adanya unsur kesengajaan dan sistematis membedakan propaganda dari komunikasi biasa atau pertukaran ide secara bebas. Setelah Perang Dunia I, propaganda telah mendramatisasi efek media massa.Propaganda yang digabungkan dengan media massa akan menghasilkan efek yang luarbiasa. Sebuah propaganda dapat berjalan dengan menyederhanakan isu-isu yangkompleks dan terus menerus mengulangi isu-isu tersebut. Laswell pernah mengatakan, propaganda semata-mata adalah kontrol publik. Dapat juga diartikan propaganda dilakukan untuk mempengaruhi atau mengontrol opini pihak yang menjadi sasaran propaganda (Laswel dalam Nurudin, 2001;63). Suatu pesan dapat efektif atau tidak, tersebar luas atau tidak, sangat bergantung pada ketepatan dalam memilih media tersebut, salah satunya melalui media elektronik, yakni televisi (Laswel dalam Nurudin, 2001;63).

Upaya korea selatan dalam melakukan propaganda kepada negara lain dengan media drama televisi bukan hal yang baru terjadi, Narasi mengenai negara Korea Utara dan Korea Selatan bersatu, tidak ditampilkan dalam program acara televisi dokumenter melainkan dibuat narasi dalam serial drama televisi fiksi, The King 2 Hearts, yang di dalam narasi ini juga terkandung unsur-unsur romantisme, action, serta setting pemerintahan yang berbeda. Adapun sebelum The King 2 Hearts ini diproduksi, terdapat serial drama televisi yang juga memiliki narasi mengarah ke unifikasi Korea, yakni IRIS 1(tahun 2009). Narasi IRIS 1 lebih menceritakan mengenai beberapa agen rahasia yang bekerja di National Security Service (NSS)Korea Selatan. Namun, narasi IRIS 1 lebih kuat menceritakan mengenai cinta, kebencian, pengkhianatan hingga mata-mata dari Korea Utara dan Selatan dibandingkan narasi mengenai unifikasi (Korean Culture and Information Service, 2011).

\section{Simpulan}

Dalam skema sederhana dapan penulis temukan sebuah kesimpulan bahwa produk-prouduk budaya populer Korea Selatan dimana Drama Korea atau K-Drama adalah salah satu jenisnya, saat ini bukan lagi produk industri hiburan semata. Narasi dan plot penceritaan yang menjadi kekuatan utama K-Drama diakui memiliki pesan-pesan intrinsik berupa propaganda yang dipandang sebagai soft power dan bentuk national branding Korea Selatan kepada negara lain. Jika dipandang dalam konteks perdagangan 
internasional, pendapatan dari export produk K-drama memang terbilang besar, namun tidak cukup signifikan untuk menjadi berbahaya bagi perekonomian negara sebesar Tiongkok, namun dari segi politik internasional dan hubungan diplomatik internasional, hubungan segitiga yang rumit antara Tiongkok, Republik Korea dan Republik Rakyat Korea (Korea Utara) dapat saja dipandang sebagai gangguan kepentingan nasional jika citra Korea Selatan yang digambarkan dalam KDrama tersebut mengakar dan menancap betul di benak rakyat Tiongkok. Maka kesimpulan penulis, dibanding sebuah langkah perdagangan internasional, aksi boikot produk K-Drama oleh Tiongkok lebih bisa dipandang sebagai sebuah langkah diplomatik negara dalam melindungi kepentingan nasionalnya. Tindakan ini dapat juga sebuah pernyataan sikap politik secara internasional.

\section{Daftar Pustaka}

Amiruddin, dan H.Zainal Asikin, 2003, Pengantar Metode Penelitian Hukum, PT. Raja Gravindo Persada, Jakrta.

Brown, Chris, 2001. Understanding International Relations, 2nd ed., New York: Palgrave.

Jackson, Robert dan Georg Sorensen, 2005, Pengantar Studi Hubungan Internasional, Pustaka Pelajar, Yogyakarta.

Johari, J.C., 1985, International Relations and Politics (Theoritical Perspectives), New Delhi: Sterling Publishers Private Limited, hal. 9

Jowett, G.S. and V. O'Donnell, 2010, Propaganda and Persuation, $5^{\text {th }}$ Edition,
Korean Culture and Information Service, 2011, K-Drama : A New TV Genre With Global Appeal, Republic Of Korea, Seoul.

Laswel dalam Nurudin, 2001, Komunikasi Propaganda, Remaja Rosda Karya, Bandung.

Papp, Daniell S, 1997, Contemporary International Relation, Frameworks for Understanding, Allyn and Bacon, United States of America.

Plano, Jack C and Roy Olton, 1999, Kamus Hubungan Internasional dan Globalisasi Ekonomi, Ghalia, Jakarta.

Sage Publication, California.

Simpson, Smith dalam Sumaryo Suryokusumo, 2000, Praktik diplomasi, Penerbit STIH IBLAM, Depok.

Soekanto, Soerjono, Pengantar Penelitian Hukum, UI-Press, Jakarta.

Viotti, Paul. R. dan Mark V. Kauppi, 1999, International Relations Theory: Realism, Pluralism, Globalism and Beyond, Allyn and Bacon, Boston.

Walts, Stephen. M, 1998, International Relations: One World Many Theories, Foreign Policy Spring.

Warsito, Tulus \& Wahyuni Kartikasari, 2007, Diplomasi Kebudayaan Konsep dan Relevansi Bagi Negara Berkembang : Studi Kasus Indonesia, Penerbit Ombak, Yogyakarta.

\section{Internet}

Batora, Josef, 2005, Multistakeholder Public Diplomacy of small and medimum-sized states: Norway and Canada Compared, makalah, dipresentasikan dalam 
International Conference on Multistakeholder Diplomacy, Mediteranian Diplomacy Academy, 11-13 Februari 2005, Malta, diakses dari www.diplomacy .edu tanggal 11 Januari 2017 pukul 20.33 WIB.

Chosun Ilbo. 2012. K-Pop Leads Record Earnings from Cultural Exports. [Online]. http://english.chosun.com/site /data/html_dir/2012/02/07/2 012020700892.html. Diakses pada tanggal 15 Januari 2017 pukul 20:58 WIB

CNNIndonesia.com, 2016, Menonton Drama Korea Makin Mustahil di China, diakses dari http://www.cnnindonesia.com/ hiburan/20160808111809220-149854/menonton-dramakorea-makin-mustahil-dichina/, pada tanggal 12 januari 2017 pukul 23.17.

Joseph S. Nye, Jr., 2011, Public Diplomacy and Soft Power, diakses dari http://ann.sagepub.com/conten t/616/1/94.full.pdf. Pada tanggal 12 januari 2017 pukul 22:57.

TabloitBintang.com, 2016, Rating Tembus 39 Drama "Descendant of The Sun" Cetak Rekor Penjualan, diakses dari http://www.tabloidbintang.com /articles/asia/korea/35555rating-tembus-angka-39-dramadescendants-of-the-sun-cetakrekor-penjualan, pada tanggal 12 Januari 2017 pukul 23:17. 